\title{
Making a star on the small screen: The case of Mina and RAI \\ Rachel Haworth, University of Hull
}

\begin{abstract}
Anna Maria Quaini (née Mazzini), or Mina as she is more commonly known, is a prolific Italian pop singer who rose to fame in the late 1950s. She was particularly dominant from the mid-1960s to the mid-1970s, before her retirement from television appearances in 1974 and public performances in 1978. In particular, it was her relationship with and continued appearances on Radiotelevisione Italiana/Italian Radio-Television (RAI) programmes during this dominant period, which helped to cement her popularity with Italian audiences. This article examines Mina's celebrity status through a detailed analysis of the construction of her star persona in a televisual context, taking as case studies her appearances on three RAI television series: Studio Uno/'Studio One’ (19611962), Canzonissima 1968/‘Lots of Songs 1968’ (1968-1969) and Teatro 10/‘Theatre 10’ (1972). A comparative reading of her performances on these variety shows enables us to evaluate the extent to which RAI facilitated the construction of Mina's star persona according to a specific set of cultural and ideological values. Ultimately, this article demonstrates the ways in which Mina's evolving celebrity came to challenge the homogenizing mission of RAI during the period.
\end{abstract}

\section{Keywords}

Mina

RAI 


\section{Studio Uno}

Canzonissima 1968

Teatro 10

stardom

celebrity

Mina (born Anna Maria Mazzini, 1940) is a prolific Italian pop singer who rose to fame in the late 1950s and was particularly dominant from the mid-1960s to the mid-1970s. Her career has spanned over 50 years and she has released over 70 albums, still continuing to release new material despite having given up live and television performances by the end of the 1970s. She has significant celebrity status within Italy yet the ‘starification’ process (Morin 2005) to which she has been subjected has resulted in the construction of a particular star persona. Mina's official website, for example, highlights that:

for Italians, Mina is an icon on the same level as our other great 'labels' which indicate exceptional quality throughout the world, like Ferrari or Fellini for example. In the Italian collective imagination, Mina is part of our heritage and a source of pride. Mina personified the role of talented singer and stage diva in concert, on television and in song. She was an intrinsic part of the history of Italian television during the 1960s and 1970s [...]. (Anon. 2011) ${ }^{1}$ 
The present article explores one element of the construction process of Mina's star persona, identified in the above biography: the role of Italian television during the 1960s and 1970s in making Mina a household name and cementing her status as an Italian star. It concentrates specifically on the relationship Mina had with Radiotelevisione Italiana/Italian Radio-Television (RAI), Italy's primary and state-funded network of television and radio channels, and the only broadcaster during the period in question. After providing a brief introduction to Mina, and an overview of the cultural significance of the RAI network, the article focuses on Mina's appearances on three specific television series during the 1960s and 1970s: Studio Uno/‘Studio One’ (1961-1962), Canzonissima 1968/'Lots of Songs 1968' (1968-1969) and Teatro 10/‘Theatre 10’ (1972).

These case studies serve to explore the control and influence exerted by RAI on Italian society in the 1960s. Monteleone has identified that RAI's programming in this period was determined by the desire to create a homogenous viewing public (2005: 346). This involved the transmission of a particular set of values, roles and behaviours embodied by presenters and actors/characters. In the context of Mina, this set of values was determined by the male gaze (Mulvey 1975) of the network's male producers, directors and managers. The filming, editing and production processes of the three shows constructed a specific identity for Mina. Its function was to demonstrate to viewers the appropriate and accepted way of behaving for Italian women during the 1960s and to encourage female viewers to internalize such values. Yet during the period 1961-1972, Mina moved away from the image of 'proper and controllable woman' sought by RAI, to become her own diva. This article therefore traces the development of Mina's star persona in the context 
of the greater social current of 1960s Italy and the ever-evolving role of the Italian woman.

\section{Anna Maria Mazzini, aka Mina}

Prior to her involvement in Studio Uno, Mina’s star persona had already been mediated to a large extent by Italian television. Although her singing career had begun in September 1958, Borgna explains Mina’s rise to national fame took place in 1959 following appearances on two of the most popular television shows of the period: Il musichiere/‘The Songwriter’ hosted by Mario Riva, and Lascia o raddoppia?/‘Leave it or double it?' hosted by Mike Bongiorno (Borgna 1999: 72). ${ }^{2}$ These early television appearances functioned to reinforce Mina's popular appeal and to highlight her willingness to use her body and her sexuality in her performances. This helped her to stand apart from other young, female singers concurrently emerging on the Italian pop music scene, as Borgna explains:

just like, and indeed more often than her colleagues, Mina expressed herself with her voice but also with her body. Indeed, with the arrival of television, the physical would begin to characterize the launch of a new singer. [... Mina] would be unashamedly photographed in audacious 'two piece' outfits or even more skimpy dresses, and always in the company of different men. She thus downplayed the importance of sex, [...] making her sexual activities natural and unproblematic. (1999: 73) 
Borgna's reading in fact points to a turn towards a more overtly sexualized representation of women generally during the late 1950s and early 1960s. From 1945 onwards, women became more visible within Italian society and there was a more open emphasis on sexuality and its indirect as well as direct commercialization (Gundle 1999: 359). The trend Borgna identifies, in which the female singer's appearance, body, hair, make-up, and fashion are talked about, sexualized, and ultimately commodified as a way of 'selling' a star and a performance, can be seen as the direct result of this shift in outlook and opinion as regards female beauty and bodies. It is perhaps not surprising, then, that constructions of Mina's star persona should focus on her appearance, clothes, gestures and behaviour, all of which have arguably become 'object[s] of narcissistic cultivation in a consumerized sense of self' (Gundle 2002: 107). They function to maintain the male gaze, playing to and signifying determining male desire within the male-dominated popular music industry (Mulvey 1975: 11). In a way, Mina’s persona had always constituted a vehicle for ideas, behaviours and values but it was to be up to RAI and the determining male gaze of the network's directors to decide which values she should embody in her appearances on Studio Uno, Canzonissima 1968 and Teatro 10.

It is important to underline here, however, that her first role on Studio Uno did not serve to introduce the Italian public to the concept of Mina as a star: she had already become firmly established as such prior to this moment, thanks to her much anticipated performances at the Sanremo Festival in 1960 and 1961. Borgna recalls how the audience began to applaud during the performance, and that flowers were thrown onto the stage at the end of the song, 'a homage which no other singer received' (1999: 80). Mina the star had arrived and it was widely assumed that she would go onto win the 1961 Festival, but 
the victory that year went to her rival, Milva, instead. Mina declared her intention to never again perform at the Festival, and withdrew somewhat from Italian popular music circles, heading to Japan and Venezuela on tour. As a result of her absence from the limelight, her appearance on Studio Uno was much anticipated (Anon. 1961). The stage was set for the return of the 'super-singer' (Anon. 1961), whose contact with her public was to be via the 'intimate medium' of television, and administered specifically by RAI (McLuhan 2001: 346).

\section{RAI in the 1950s, 1960s and 1970s}

In order to fully appreciate the significance of Mina's involvement in and appearances on Italian television, it is necessary to consider the broader political and administrative context of RAI in this period, the changes it underwent and its approach to programming and to its audience. Since its foundation, RAI had always been subject to top-down political control by the Christian Democrat (DC) governments of the period and also from the Vatican. In the early 1950s, when television broadcasting was established in Italy, both the DC and the Vatican appreciated the ideological importance and potential power of the new medium. When describing this period, Padovani highlights the

attention to the moral and pedagogical duties of the medium [which were] the foundation of the DC's political culture in RAI, especially that of its left wing, traditionally more involved in socially oriented activities. For the Catholic bloc, television was an important tool of social intervention, an occasion not to be wasted to make Catholic culture appealing to the masses. (2005: 69) 
The result of this interventionism was the creation of a list of topics, including divorce and extramarital affairs (particularly significant given later events in Mina's career), which were not to be discussed or given airtime. Importantly, the 1950s was the decade of the economic miracle and the increased urbanization of Italian society, resulting in the ever-increasing popularity of television. Indeed, all three of the RAI series analysed here drew large numbers of viewers, regularly reaching more than twenty million viewers on an average per week. Television, then, was the ideal vehicle for the transmission of ideals and values to a large proportion of the Italian population. But the negative consequences of this success are clear: Chiarenza explains that 'the less well-educated viewing public [were] exposed to the suggestive power of consumerism' (2002: 92), suggesting that television had become a purveyor of a 'consumerized sense of self' (Gundle 2002: 107). During the late 1950s and early 1960s, Italian society experienced further changes due to the resultant buying power afforded by the economic boom, and the identification of 'youth' as a class in its own right. These changes necessitated a 'more articulated and ideological - rather than simply political or propagandistic - use of television' (Padovani 2005: 73). This use was particularly evident from 1961, following the arrival of Ettore Bernabei as director general of RAI. Bernabei's approach to programming remained paternalistic, pedagogical and political: he believed that the public were 'in need of guidance $[\ldots$ and $]$ needed to be cared for, even protected from harmful information; therefore television could convey only information that was considered appropriate by the broadcaster's leadership' (Padovani 2005: 80). Programmes had to educate and entertain, in line with strict political, ideological, religious and gender ideals, as approved 
by the DC. These are the primary characteristics of the homogenizing mission of RAI during this period, which resulted in a particular approach to programming and to content. For example, Monteleone explains that

in the decade 1960-70, RAI was dedicated to the creation of as homogenous a popular viewing public as possible. This project was facilitated by the ever more popular use of sound, and resulted in the expansion of programming in three thematic areas: variety shows and light entertainment programmes, which, during the 1960s, reached the level of total entertainment, once freed from American influences; easy-listening music, and especially that produced specifically for the big song shows; and cultural and informative programming. (2005: 346, original emphasis)

Studio Uno, Canzonissima 1968 and Teatro 10 firmly belong to this programming rationale, and specifically to the genre of variety shows and light entertainment. How these (and other) programmes functioned to create a homogenous audience is not explored by Monteleone. I would suggest, however, that an important element of this process is RAI's use of particular presenters, acts and guest stars. These represent, transmit and encourage the acceptance and internalization by the audience, of a specific set of values (be they cultural, political or broadly ideological, for example), which function to homogenize the viewing public. Mina is a case in point: her star persona was transmitted by RAI to approximately 40 per cent of the Italian population during the 
1960s and 1970s, making her an ideal medium for the embodiment and transmission of such values. This is particularly evident in her appearances on Studio Uno.

\section{Studio Uno, 1961}

Studio Uno was a successful variety show with four series broadcast between 1961 and 1966. The first series constitutes my focus here, as this is the first occasion on which Mina takes centre stage on Italian television programming. The show was created and directed by Antonello Falqui and was broadcast weekly on Saturday nights in the prime time slot from 21 October 1961 to 13 January 1962. It was clearly influenced by similar, international programmes: the format of song and dance segments, always accompanied by the house orchestra, sketches and interviews with special invited guests, drew inspiration from the American variety shows of the 1950s, including most obviously The Ed Sullivan Show (1948-1971). In the 1961 series of Studio Uno, Mina is a staple performer, giving weekly song performances and being involved in occasional sketches with invited guests and other regular performers. She is the primary female performer and her appearances enable us to delineate the ways in which she is constructed as a 'proper' woman by RAI, and to explore the extent to which her star persona remains true to such a construction during the series.

All of Mina's performances take a similar format, filling the last slot in the programme and thus closing each show. She is always introduced by the Boys dance troupe; the camera then cuts to Mina standing at the back of the house orchestra that is split in two to leave a path through the players to the front of the stage area. As the audience applauds, she awkwardly acknowledges their welcome and makes her way through the orchestra to 
stage front. Once the applause has died down, she speaks directly to the audience via the camera, addressing the ladies and gentlemen watching, and introducing the songs she will perform during the segment. Sometimes, the segment also features sketches and dances with invited guests, such as Franca Valeri (30 December 1961), or with other regular performers on the show, such as Don Lurio, the show's choreographer (28 October 1961). For these performances, Mina is often dressed in fine cocktail dresses, usually black, knee length and sleeveless, her hair and make-up are always impeccable, and she is clearly cast as the showgirl and star of the show. But it is the performances that showcase her star status, which begins with her singing talent but goes onto signify much more by the end of the series.

It is clear that Mina is a popular music star and that her celebrity status is predicated on her singing talents. Song forms an important part of her role on the show. She in fact performs a range of songs in different languages and of different styles; this breadth of material serves to showcase Mina's singing talents. She deserves the label 'star' because of her extraordinary abilities, which begin to mark her not as a mere human but rather as a divine diva (in the Italian sense), encompassing the notions of the superhuman that are essential in the creation of a star (Morin 2005: 25). Richard Dyer points out that stars who are labelled as such 'because they are exceptional, gifted, wonderful' must also possess skill 'at being a certain sort of person or image' (1998: 16-17), which can be easily consumed by audiences Importantly, Mina’s appearances on Studio Uno serve to underline her many talents and thus reaffirm her star status that can easily be accessed by audiences via television. As a result, Mina proved to viewers 'to be not only a yeller but an all-round interpreter able to adapt her voice to various genres of popular music' and 
was thereby granted the image of 'sophisticated performer' (Prato 2013: 166), and extraordinary popular music star.

The filming of the performances on Studio Uno emphasizes the 'extraordinary’ aspects of Mina's star persona and encourages the audience to accept them unquestioningly: she is often in the spotlight, distanced from the orchestra and on show for the public. Indeed, the studio lighting is often dimmed so that all the viewers can see and focus on is the star performer. She also physically fills the television screen, as the camera nearly always films in medium close-up, focusing on her face and shoulders and allowing the audience to appreciate the effort and emotions Mina puts into these performances.

There is a notable contrast between the presentation of Mina and that of other staple female performers on the series, in particular the Kessler twins. They are filmed from a distance, which allows the camera to capture their song and dance routines and to display their bodies and legs for the audience (indeed, their costumes are often figure hugging and made up of dance leggings and leotards in order to showcase their bodies and their dancing). In contrast, the presentation of Mina is not overtly sexualized. Her outfits are always glamorous and eye-catching, but remaining appropriately demure and respectable. Her make-up is never heavy or intrusive, again reinforcing a sense of respectability. Her body is always part of the performance but, with the exception of one song in the third episode, it is her voice that takes centre stage. Her body, then, emphasizes and supports the dynamics and emotions of each song. Indeed, the apparent intimacy of some of the performances (e.g., 'The Man I Love’3 (11 November 1961), 'Un tale/A guy' (30 December 1961), and the medley of songs she performs in the final episode of the season (6 January 1962)), created by the continued close-up, the use of backlighting to silhouette 
the performer, and the low level of studio lighting generally, enables the audience to clearly identify each emotive element of the performance on Mina's face and upper body, her arms in particular. But this, seemingly, is not a show put on for the spectators; rather, they are witnessing Mina's enjoyment of and passion for music. She uses her whole body to perform the song, and her arm gestures signal an all-encompassing aspect of her performance that encourages the viewer to join her in appreciating the song. Her body and face become the stage for her emotions, and the audience believes that they are witnessing an authentic response to each of the songs being performed, which, in turn, becomes their response as they watch Mina’s interpretation.

When the audience is encouraged to gaze at Mina's body during her performance of 'Fascinating Rhythm' (4 November 1961), for which she performs a dance routine in black, figure-hugging dance leggings and top, the performance is filmed at a distance. The camera encourages the viewer to voyeuristically gaze at Mina, but the personal, intimate quality associated with her other performances on the series is lost. In a way, this could be any one of the female dance performers from the show. The potential challenge to Mina’s respectability is nullified through the depersonalizing distance of the camera. Respectability is therefore a key to Mina's star persona on Studio Uno. The construction of Mina as respectable imbues her with a 'moral authority' (Skeggs 1997: 5); she is a source of knowledge and, more significantly, an educator of the audience, an appropriate function in the context of RAI's pedagogical and homogenizing mission. Indeed, there are segments of the show in which Mina directly addresses her audience and seeks to instruct them in the music and television business. For example, she presents a segment in which she explains the process of overdubbing to the audience, demonstrating the 
different stages of the process by recording the different vocal parts of one of her songs, 'Prendi una matita'/‘Take a Pencil'. Such demonstrations and explanations render Mina’s 'art' accessible to her public, and serve to bridge the gap between the star and her audience. As Brioni points out, here 'she is an educator, connecting her role to the Italian tradition of instructive television' (2014).

But Mina is also able to instruct viewers indirectly in broader moral issues, through her appearance, make-up, body language, clothing and gestures. As Skeggs notes,

the definition of female respectability became part of the wider formation of domestic ideology and the propagation of home and family values. It brought together domesticity and sexuality in opposition to each other. Respectability was organized around a complex set of practices and representations which defined appropriate and acceptable models of behaviour, language and appearance; these operated as both social rules and moral codes. (1997: 46)

Respectability for women, then, evokes domesticity, appropriateness and acceptability in a social and cultural context. A respectable woman thus signifies socially acceptable behaviours that highlight the domestic role and reproductive function of women within society. In Italy, 'representations of women occupied a key place in the imagery of the nation and virtually every political force or movement that aspired to, or which actually exercised, national leadership sought in some way to appropriate or make use of them' (Gundle 2007: xviii-xix). In this context, Mina's appropriately respectable star persona is constructed and then used by RAI to promote appropriate models of behaviour and 
appearance for women in 1960s' Italy. Mina is thus objectified on Studio Uno. She is the physical object on-screen of a determining male gaze, which insists that she 'holds the look, plays to and signifies male desire' (Mulvey 1975: 11), in an appropriately demure and respectable way of course. But she is not merely the object of an overtly sexual desire (although clearly this plays a part in her representation); she also signifies male desire in that she is seen to conform to the determining male societal and behavioural values of the period. As a constructed object, she can be controlled and used by RAI to promote such values to audiences in the studio and at home.

But such a conclusion suggests a passivity and lack of engagement on the part of Mina as regards the use made of her star image by RAI, which is inaccurate. There are in fact instances throughout the first series of Studio Uno where Mina challenges her own 'respectable' persona. She often winks at the camera either when entering the stage or at the conclusion of her performances, suggesting another side to her persona that is not accessible during the show, and alluding to a sense of complicity between Mina and the audience as regards her 'real' personality (although it can be argued that this 'real' persona always remains a construction). Special performances occasionally hint at a less respectable aspect of Mina’s persona; Franca Valeri, for example, explains that 'I knew that men like you a lot but I have discovered that women like you as well' (30 December 1961). The allusion here is to Mina's relationships with a variety of different men during the early 1960s, which were headline celebrity news, although naturally this is not referred to again during the segment. Bennett makes the point that in the context of television personalities, there is often 'an elision of on-/off-screen self, whereby they have been conceptually and culturally understood in terms of authenticity: merely being 
or playing "themselves"' (2011: 6). Although Mina is more than a television personality, this equation of the on-/off-screen self is important. The 'celebrity apparatus' that surrounded Mina and the broadcast of Studio Uno ensured that Mina's private life formed an integral part of audience responses to the show (Santoro 2002: 120). As a result of the weekly reviews of the show in Radiocorriere/Radio Times and other magazines, audiences remained engaged with the show and had access to Mina's on- and off-screen life.

One particular aspect of Mina's private life was to pose a specific challenge to her 'respectable woman' persona and to the RAI network more generally: in January 1963, Mina announced she was expecting a baby with Corrado Pani, a married actor with whom she had been having an affair. The story received much media coverage throughout the year, as Pani sought to annul his marriage and Mina prepared herself to become a mother. As a result of the announcement, however, Mina was banned from appearing on television by the RAI network and thus dropped from Studio Uno. Extramarital affairs and pregnancies clearly challenged the conventional ideas of the family and domesticity promoted by the network. Audience demand for the star, however, forced the broadcaster to rescind the ban the following year, allowing Mina a triumphant return to the final series of Studio Uno in 1965. Yet it is clear from her involvement in this series that Mina's star persona had evolved, arguably because of the media attention given to her off-screen life, which functioned to construct a different kind of persona and then became an integral part of Mina's celebrity status. For example, in this final series, Mina introduces a segment entitled 'l'uomo per me/He's the man for me', which features a performance with a different male guest star each week; in the 
context of the 1963 scandal, the irony of the title and the format of the segment is clear. Her persona is more than the demure starlet of the 1961 series, and has in fact begun to challenge RAI's initial construction of Mina as a respectable and controllable woman. Significantly, audiences are aware of this challenge and we can thus argue that although the image of Mina is constructed as 'proper woman' by RAI, audiences are aware of the fabricated nature of this construct thanks to the media coverage of the 1963 scandal. Indeed, Dyer explains that 'stars, by virtue of being experienced [...] and individuated [...], and having an existence in the real world, serve to defuse the political meanings that form the [...] point of departure of all media messages' (1998: 27). As a result of the newspaper coverage of and attention paid to Mina's private life, the audience is able to experience and individuate Mina. They are thus aware of the starification process to which she has been subjected by RAI and, as a result, are less likely to accept and internalize the values she is said to embody.

\section{Canzonissima, 1968}

The evolution in Mina's star persona, and the challenges it poses to the image of Mina as ‘proper woman’, is evident on Canzonissima 1968, and is demonstrated by Mina’s performances and overall style on the series. This popular musical variety programme was broadcast by RAI from 1956 to 1975, with a break from 1963 to 1967 . The main element of each series was a song competition, although there were also sketches, comedy and dance routines, and the programme was always linked to the Italian national lottery. According to Monteleone, Canzonissima above all other programmes 'functioned as the great homogenizing agent of the viewing public through the pairing of the 
attractive and seductive variety show apparatus with that tried and tested component of popular entertainment [...], song' (2005: 347). This would suggest that the series played a significant role in the homogenizing mission of RAI during this period. However, although the spectacular and entertaining programme format and the inclusion of songs were clearly part of the appeal to audiences, I would again suggest that, as was the case with Studio Uno, the homogenization of the audience was to be achieved through specific performers and presenters. These functioned as vehicles for a particular set of values and ideals: viewers identified with these stars and 'wanted to be like them'. This meant assuming, to an extent, the persona of the performer and/or presenter and internalizing the values they represented.

Canzonissima 1968 was broadcast from 28 September 1968 to 6 January 1969 on RAI 1 and featured song performances each week by artists involved in the competition, judged by different guest judging panels and by the general public. Mina acted as co-host of all fifteen episodes of the series together with Walter Chiari and Paolo Panelli, both established actors and presenters on Italian television and radio. The hosts performed comedy routines and sketches as part of each programme, and were responsible for recording the votes for each song as they were announced by the judging panels throughout the show. Significantly, the three co-hosts take turns at writing the number of votes on the chalkboard, suggesting they were of equal importance and stature. All three also performed solo routines; in the case of Mina, this took the form of a weekly song performance, in which she often presented a musical medley around a specific theme. Given the importance of song to the programme, to the variety genre more broadly, and 
to the construction of Mina's star persona, these are the performances that will constitute the main focus of my analysis of Canzonissima 1968.

It is again important to note the emphasis placed on Mina’s voice in these performances. As on Studio Uno, the songs and medleys Mina performs on Canzonissima showcase her vocal talent, range and abilities. However, these are seemingly more polished performances than those from Studio Uno. Mina interacts much more obviously with the camera as she sings, deliberately performing and directing her gestures towards the television viewers and not her studio audience. The filming of these songs lends to this polished feeling: the angle adopted by the camera, and the balance of facial close-ups, long shots of the stage and full body shots of Mina whilst she is singing, reveal the editing process and the resultant construction of a particular type of performance that is very much dependent on the theme of the song being performed. For example, emotive performances of songs such as 'Quelli che hanno un cuore'/‘Anyone who has a heart' (Italian version of Dionne Warwick’s 1963 hit) (14 December 1968) are filmed in a long shot in close-up of Mina's face (which stages all the emotions of a tortured lover), whereas songs like 'E sono ancora qui'/‘And I'm still here' (28 September 1968) are shot from a distance, as Mina physically distances herself from the orchestra onstage, and instead positions herself in the midst of the studio audience. Such interactions with the home and studio audiences draw the viewers into the performances, and focus their attention not only on Mina’s vocal talents but also on her ability to consummately perform her songs. She is no longer merely cast in the role of the respectable, everyday woman who happens to be talented, as seen on Studio Uno. Rather, she is the 
extraordinary performer, confident in her music and her abilities to entertain her audience.

This is particularly evident in Mina's performance style, specifically in the allencompassing arm gestures that were a feature of Mina’s earlier performance style and which are again prominent here. But there is an increased confidence in Mina's gestures on Canzonissima 1968; unlike on Studio Uno, such emotive gestures are usually accompanied by a direct gaze into the camera, suggesting self-assurance in her performance style, which was previously lacking. Indeed, Mina even satirizes her own style on Studio Uno in the Christmas letter that she sings to the audience, in which she promises to control her dramatic tendencies (23 December 1961), perhaps suggesting a self-awareness and lack of confidence. On Canzonissima 1968, there are no traces of selfdoubt. Mina is the star performer, confident and well loved by her audiences. There is now a distance between the audience and the star, as she begins to fully encapsulate the ideal of the diva. Importantly, she is prevented from fully embracing such a persona in her role as co-host, which demands a certain proximity to the audience and requires an element of the mundane (introducing the other performers, explaining the rules of the competition, acting as the punch line of her co-hosts' jokes and recording the judging panels' votes, for example). Mina’s physical appearance also suggests the conscious presentation of a diva. For Canzonissima 1968, Mina has short, dyed blond hair and wears heavy make-up and false eyelashes. She appears to be more aware of her own celebrity status and of the need to maintain such a persona, and of her own body and sex appeal. There is arguably a conscious decision here on the part of Mina to use her body to realize her star persona. 
Gundle points out that in Italy, 'there was a striking emphasis in this period on blonde women, whose chromatic aura was attributed with a variety of meanings that were all associated with the American model of the consumer society, prosperity and modernity' (2007: 171). Within this context, 'Mina, a singer whose aggressive manner led her to be dubbed "the tiger of Cremona", also dyed her hair blonde and established her own rules, scandalising public opinion by becoming an unmarried mother in 1963' (2007: 178). If these changes to Mina's physical appearance are interpreted within the context of the post-war changes in Italy, which brought increased economic prosperity, a shift towards western/Anglo-American ideals and lifestyles, and an active women's liberation movement, Mina's star persona in fact comes to embody such cultural and social shifts. Indeed, as far as the field of Italian star studies is concerned, what is of most interest is the star's 'function as a cultural symbol and conduit for ideas about gender, values and national identity' (Gundle 2008: 263). It is significant, however, that Mina’s embodiment of these post-war changes in Italian society does not obviously align with the homogenizing and educative mission of RAI, suggesting that although the network was in part responsible for the creation and dissemination of Mina's celebrity status, it was unable to control the subsequent meanings attributed to her persona by Mina herself, her management company, the music industry and the general public.

Indeed, the blonde hair, heavy eye make-up and extravagant evening gowns are not necessarily merely symbols of Mina's awareness of and attempts to shape and control her own star persona. Kathleen Rowe explores some of the ways in which women reclaim control of their identities in her study of the 'unruly woman'. She explains that the unruly woman 'through her body, her speech, and her laughter, especially in the public sphere, 
[...] creates a disruptive spectacle of herself', which functions as a source of potential power (Rowe 1995: 31). In the context of female cinema stars, and particularly Sophia Loren, Jacqueline Reich also speaks of the figure of the unruly woman, explaining that these kinds of female film characters, 'with their exaggeratedly feminine body and calculated use of performative femininity, call into question traditional masculine gender constructions and at the same time redefine the feminine' (Reich 2004: xv). When this notion of unruliness is applied to Mina, the elements of excess in her appearance and performances identified above serve to cast her as an unruly woman who is beginning to redefine the feminine. Her star persona cannot be totally controlled and thus poses a challenge to traditional gender roles and definitions of 'woman' in the Italian context which formed part of RAI’s educative and homogenizing mission.

\section{Teatro 10, 1972}

By 1972, it is clear that further meanings have been associated with Mina’s star persona, as evidenced in her appearances on Teatro 10, and that her star image is even more removed from the notion of 'proper' woman as proposed by RAI on Studio Uno. The 1972 series was the third for the variety show, which had previously aired in 1964 and 1971. The latter regularly attracted large numbers of viewers but it was Falqui's wish to bring Mina back to television screens in the 1972 series as the star of the show. Her cohost was the well-established actor Alberto Lupo, who in fact functioned as the primary host, introducing the various guest performers from the worlds of popular and classical music, theatre and ballet. Mina’s involvement was, at her request, limited as much as possible to singing, as Gottardi explains: 
Finally, at the start of 1972, Mina agreed [to return to television]. But on her terms: less talking, just singing. She would speak as little as possible, and sing a lot. But this she would do extremely well, as always, enchanting the public and dominating the stage at the expense of Alberto Lupo. (2013)

Her domination of the stage is perhaps the most striking element of all of her appearances on Teatro 10. In each show, Mina appears at least twice, as she both opens and closes the show. Additionally, she often performs a duet with invited popular music guests, including Gianni Morandi, Milva, Fred Bongusto and Lucio Battisti. Her look and performance style remain largely unaltered throughout the series and have arguably been perfected to support her star image. She always wears a black, floor-length evening gown and her make-up is heavy and dark. Morin explains that make-up functions to create a mask that 'orders the features according to a canon of beauty that can be Hellenic, Oriental, exotic, ingénue, romantic, piquant, feline, and so on' (2005: 33). More than this, however,

during festivals and sacred rites, the mask reveals a spirit, the incarnation of a genius or god. Theatre makeup perpetuates this function: it differentiates the actor on the stage from profane humanity $[\ldots]$ and invests the actor with a sacred and hieratic personality. (Morin 2005: 32) 
Mina's physical appearance on Teatro 10 encourages viewers to look at her: her 'mask' is made up of costume, make-up and hairstyle, which together function to make her a beautiful star according to the televisual and popular music canons of beauty of the 1970s (there are striking similarities between the representation of Mina and that of Barbara Streisand and Shirley Bassey, for example). She is separated from the audience and her persona is now fully that of a diva, the star and talented artist who embodies the sacred, divine, aesthetic properties required for that role (Morin 2005: 84). Her performance style on the show also exemplifies these star qualities: the typical arm gestures, now a trademark that is often accentuated by the customized long sleeves of her evening gowns, suggest an element of inclusivity to her performance, which is negated by the distance maintained from the audience and by her palpable satisfaction at the end of each performance, which is met with rapturous applause from the audience. The camera angles emphasize Mina's hard work and passion for her art during the performances. In contrast to other performers such as Milva and Marsha Hunt, who are filmed at eye level and in medium or medium long shot (so as to include full body shots in the case of Hunt), Mina is often filmed in extreme close-up from a low angle, so that the audience can carefully observe and internalize her emotions, whilst gazing upwards (even worshipfully, as Morin would have it) into the face of the diva.

To be labelled a 'diva' in a popular music context connotes an impressive vocal range and singing talent, and often a demanding, fussy and self-important personality. However, the classical roots of the anglophone term 'diva' suggests that some of its original significances (the prima donna, the astonishing soprano, the star) still apply within popular music (Lister 2001: 1-2). However, in the deification process, not all the 
elements that make a diva are equally emphasized. Technique, intelligence, musicianship and hard work are not often highlighted when discussing star qualities; instead, charisma, genius and mystique are the qualities that serve to manufacture stardom - and the star (Christiansen 1984: 11). Yet Mina belongs to the Italian popular music context and thus also embodies the connotations of diva culturally specific to Italian modernities; as well as belonging to the world of music, the label diva in Italian also evokes the film divas of early Italian cinema, with whom Mina has certain performance traits in common, notably a 'dazzling visual display' and 'an operatic heightening of emotions' (Dalle Vacche 2008: 1, 6).

Mina's star persona on Teatro 10 is constructed around the various elements listed above that connote a diva, and is particularly evident in her duet with Lucio Battisti (23 April 1972). Mina's vocal talent and range are expertly showcased here, and she often outsings Battisti who must hold the microphone to his lips in order to ensure that his voice is heard. Her appearance also draws our focus; unlike Battisti, who wears an apparently ordinary, everyday outfit consisting of a jacket and jeans, Mina wears her customary black evening gown. Her hair is perfectly styled and her make-up carefully applied. She is the glamorous star whose dazzling visual display demands attention. And she uses her face and body to stage the range of emotions evoked by the various songs that she and Battisti perform. She is the one who heightens our emotional response to the songs, as her gestures and facial expressions encourage us to feel as she feels.

By Teatro 10, then, Mina has become the consummate performer and entertainer, an icon of quality Italian cultural production as her website would have it. The potential cracks in her star image, which were identifiable in the earlier series and could be explained by a 
potential lack of confidence or cohesion between her on-/off-screen persona, are no longer evident. She is the star of the show, the prima donna and diva/diva of Italian popular music. And it is largely thanks to RAI's programming that this star persona is transmitted to, and accessed by, the Italian public.

\section{Conclusion}

This article has explored the evolution of Mina's star persona during the 1960s and 1970s as presented on Italian television. In the case of the first series of Studio Uno, Mina's star status is created and cemented by her performance on the show. Although she was an established popular music star, her weekly appearance on the series allowed her into the homes and communities of her public and made her a household name. But due to her function on the programme, her star persona was both shaped by and a challenge to a particular set of societal and behavioural values in line with RAI's homogenizing and educative mission of the early 1960s that sought to promote a set of ideal behaviours and values for the Italian woman of the period.

By 1968, and Canzonissima 1968, Mina's star persona was firmly established. Here, she is the confident, consummate performer whose excesses and unruliness result in her becoming a conduit for ideas about gender, values and national identity, which epitomize the broader cultural and social shifts of the late 1960s in Italy. It is finally in 1972 that we see Mina's star persona go beyond that of the talented performer; on Teatro 10 Mina is clearly a diva. She is the talented prima donna of the series, whose vocal talents, vocal range, emotive performance style and glamorous physical appearance mark her as extraordinary and divine. The RAI series in this instance functions to promote Mina's star 
status. She dictates the terms of her involvement in the series, and uses her weekly performances to showcase her talent to her fans.

In the context of RAI's political agenda, the network uses Mina on Studio Uno in 1961 to construct and propose an appropriate role model for viewers. This 'Mina as proper woman' model is imbued with a specific set of respectable values by the various production processes of the show (including, but not limited to, filming style, costume choices and editing). But as Mina’s personal and televisual history develop over the next decade, so does her function as role model to Italian women. She begins to represent the broader changes within Italian society taking place during the 1960s, and by 1968 it is clearly an unruly challenge to the determining male societal and behavioural values of the period. By 1972, she is the established diva, enabled as such by her fans and in turn enabling them to similarly challenge the hegemonic, masculine norms of Italian society. And it is thanks to RAI that this star persona was created, re-shaped and redefined, and then showcased to millions of Italians via the medium of television.

\section{References}

Anon. (1961), 'Varietà'/'Variety', Radiocorriere/Radio Times, 8-14 October, http://www.minamazzini.com/cronache/variet-la-rentre-di-mina/. Accessed 26 February 2014.

(2011), 'Mina', http://www.minamazzini.it/. Accessed 12 February 2014. 
Bennett, J. (2011), Television Personalities: Stardom and the Small Screen, London: Routledge.

Borgna, G. (1999), L'Italia di Sanremo/‘The Italy of Sanremo', Milan: Mondadori.

Brioni, C. (2014), 'Between two stages: Representations of youth in Studio Uno', 7th Annual Graduate Conference in Italian Studies, University College Cork, Ireland, 1 March.

Canzonissima 1968/'Lots of songs 1968’ (1968-1969, Rome: RAI).

Chiarenza, F. (2002), Il Cavallo morente: Storia della RAI/`The dying horse: A history of the RAI’, Milan: Francoangeli.

Christiansen, R. (1984), Prima Donna: A History, London: The Bodley Head.

Dalle Vacche, A. (2008), Diva: Defiance and Passion in Early Italian Cinema, Austin: University of Texas Press.

Dyer, R. (1998), Stars, London: BFI.

'E sono ancora qui'/‘And I’m still here’ in Canzonissima 1968 (1968, Rome: RAI). 
‘Fascinating Rhythm’ in Studio Uno (1961, Rome: RAI).

Gottardi, P (2013), ‘Teatro 10’/‘Theatre 10’, http://www.anni70.net/televisione/teatro10/. Accessed 9 April 2014.

Gundle, S. (1999), 'Feminine beauty, national identity and political conflict in postwar Italy, 1945-1954', Contemporary European History, 8:3, pp. 359-78.

(2002), 'Hollywood glamour and mass consumption in postwar Italy', Journal of Cold War Studies, 4:3, pp. 95-118.

(2007), Bellissima: Feminine Beauty and the Idea of Italy, New Haven, CT and London: Yale University Press.

(2008), 'Stars and stardom in the study of Italian cinema', Italian Studies, 63:2, pp. 261-66.

Il musichiere/'The Songwriter' (1959, Rome: RAI).

Lascia o raddoppia?/‘Leave it or double it?’ (1959, Rome: RAI).

Lister, L. (2001), 'Divafication: The Deification of Modern Female Pop Stars’, Popular Music and Society, 25:3-4, pp. 1-10. 
'The Man I love’ in Studio Uno (1961, Rome: RAI).

McLuhan, M. (2001), Understanding Media: The Extensions of Man, London: Routledge.

Monteleone, F. (2005), Storia della radio e della televisione in Italia: Costume, società e politica/‘History of Italian radio and television: Traditions, society and politics’, Venice: Marsilio.

Morin, E. (2005), The Stars (trans. R. Howard), Minneapolis, MN: University of Minnesota Press.

Mulvey, L. (1975), 'Visual pleasure and narrative cinema', Screen, 16:3, pp. 6-18.

Padovani, C. (2005), A Fatal Attraction: Public Television and Politics in Italy, Lanham, MD: Rowman \& Littlefield.

Prato, P. (2013), 'Virtuosity and populism: The everlasting appeal of Mina and Celentano', in F. Fabbri and G. Plastino (eds), Made in Italy: Studies in Popular Music, New York: Routledge, pp. 162-71.

'Prendi una matita'/‘Take a pencil' in Studio Uno (n.d., Rome: RAI). 
'Quelli che hanno un cuore’/‘Anyone who had a heart’ in Canzonissima 1968 (1968, Rome: RAI).

Reich, J. (2004), Beyond the Latin Lover: Marcello Mastroianni, Masculinity and Italian Cinema, Bloomington, IN: Indiana University Press.

Rowe, K. (1995), The Unruly Woman: Gender and the Genres of Laughter, Austin, TX: University of Texas Press.

Santoro, M. (2002), 'What is “cantautore?”: Distinction and authorship in Italian (popular) music', Poetics, 30:1-2, pp. 111-32.

Skeggs, B. (1997), Formations of Class \& Gender: Becoming Respectable, London: Sage.

Studio Uno/‘Studio One’ (1961-1962, Rome: RAI).

Teatro 10/‘Theatre 10’ (1972, Rome: RAI).

'Un tale’/‘A guy’ in Studio Uno (1961, Rome: RAI).

\section{Contributor details}


Dr Rachel Haworth is Lecturer in Italian at the University of Hull (UK). Her research interests lie broadly within the area of Italian popular culture, and, specifically, in popular music. She is interested in questions of gender, performance, stardom, legitimation and value within Italian popular music. She has published on the importance of media commemorations, and the notion of performance in the chanson française in the 1960s in the journal Contemporary French Civilization and Barbara Lebrun's edited volume Chanson et performance: Mise en scène du corps dans la chanson française et francophone/‘Chanson and performance: Staging the Body in the chanson française and francophone' (L'Harmattan, 2013), respectively, and on the figure of the singersongwriter as performer in French and Italian popular music in the Journal of European Popular Culture. She is author of From the chanson française to the canzone d'autore in the 1960s and 1970s: Authenticity, Authority, Influence (Ashgate, 2014/2015, forthcoming).

\section{Contact:}

School of Languages, Linguistics and Cultures, University of Hull, Cottingham Road, HULL, HU6 7RX, UK.

E-mail: r.haworth@hull.ac.uk

Notes

\footnotetext{
${ }^{1}$ Unless otherwise stated, all translations from the original Italian texts are mine.
} 
${ }^{2}$ Il musichiere/‘The Songwriter’ and Lascia o raddoppia?/‘Leave it or double it?’ were inspired by and based on the format of the US programmes The $\$ 64,000$ Question and Name That Tune, respectively.

${ }^{3}$ To maintain consistency throughout this article, all information about the songs cited refers to the versions that Mina performed on television during the three series considered here. Whilst these songs may subsequently have been released as singles or on albums, there are potential differences between the studio and 'for television' versions that could be misleading. 